\title{
ATRIBUTOS DO RELEVO DERIVADOS DE MODELO DIGITAL DE ELEVAÇÃO E SUAS RELAÇÕES COM SOLOS
}

\section{LANDSCAPE ATRIBUTES DERIVED FROM DIGITAL ELEVATION MODEL AND RELATIONSHIPS WITH SOILS}

\author{
Angelo Evaristo SIRTOLI ${ }^{1}$ \\ Claudinei Taborda da SILVEIRA² \\ Luiz Eduardo MANTOVANI ${ }^{3}$ \\ Ana Rosa dos Anjos SIRTOLI ${ }^{4}$ \\ Chisato OKA-FIORI ${ }^{5}$
}

\begin{abstract}
RESUMO
O presente estudo aborda as relações entre solos e atributos do relevo derivados de um modelo digital de elevação (MDE) numa área localizada sobre a Formação Guabirotuba, Aluviões e depósitos coluvionares secundários. A partir do modelo de elevação digital derivaram-se seis atributos primários: elevação, declividade, radiação solar global, plano e perfil de curvatura e orientação das vertentes e um secundário, o índice topográfico de umidade (TWI). Foram avaliadas as interações que ocorrem entre geologia e os atributos derivados do MDE com os solos mapeados na área. Os resultados mostraram que a geologia juntamente com o TWI está estreitamente relacionada com os solos de caráter hidromórfico. Os Latossolos estão predominantemente em plano e perfil de curvatura, divergente e convexa, enquanto que os Cambissolos em convergente/divergente e côncavo e a associação Gleissolos e Organossolos em convergente/planar e retilínea. As vertentes mais declivosas orientadas para o sul apresentaram solos com matiz entre 7,5 YR a $10 \mathrm{YR}$, mais amarelados. Os solos com caráter hidromórfico e os Latossolos localizam-se em relevos mais aplainados enquanto os Cambissolos estão nas maiores declividades. As posições mais elevadas e preservadas dos processos de entalhamento da paisagem apresentam predominantemente Latossolos. Os Cambissolos estão em posições intermediárias e nas menores altitudes encontram-se os solos de caráter hidromórfico.
\end{abstract}

Palavras-chave: relações solo geomorfologia, MDE, formação Guabirotuba

\begin{abstract}
The present study approaches the relationships between soils and attributes of the landscape derived from a digital elevation model (DEM) in a area over the Guabirotuba Formation formed by alluvial and secondary deposits colluvial fans deposits. Starting from the digital elevation model we did derived six primary landscape attributes: elevation, slope, global solar radiation, plan and profile curvature. A secondary attribute, the topographical index of humidity (TIW) was also created. The eventual interactions between the geology and the derived attributes of DEM with the soil mapped in the area were evaluated. The results showed that combination of the geology and TWI data can explain occurrence of Gleyssols and Histosols. The major soils formations were located in the following conditions: Ferralsols - plan landscape with curvature plan and profile, divergent and convex; Cambisols - convergent/divergent and concave; and the association Gleysols and Histosols convergent/ planar and flat. The high degree slopes facing south presented matiz betwen 7,5 YR - 10 YR, yellowish soil color. The Ferralsols class and soils with hydromorphic character were located in flat landscape while Cambisols were situated in the largest steepness. The highest positions which represented well preserved soil again loss, had predominantly Ferralsols. The Cambisols were situated in intermediate positions and in the lowest altitudes were found soils of character hydromorphic.
\end{abstract}

Key words: soil geomorphology relationship, DEM, Guabirotuba formation.

\footnotetext{
1 Programa de Pós Graduação em Geologia da UFPR. asirtoli@ufpr,br. Autor para correspondência.

2 Programa de Pós graduação em Geografia da UFPR.

3 Professor do Departamento de Geologia da UFPR.

4 Professora da UERGS - Unidade de Erechim.

5 Professora do Departamento de Geografia da UFPR.
} 


\section{INTRODUÇÃO}

Os modelos solo-relevo mais quantitativos estão se tornando conhecidos como novo paradigma para o levantamento de solos, bem como para o entendimento e predição dos padrões naturais do solo e já fazem parte das tendências dos levantamentos (HUDSON, 1992).

As diferentes variáveis passíveis de obtenção num Sistema de Informações Geográficas (SIG) podem dar suporte à classificação da paisagem, fornecendo uma segmentação da mesma em ambientes topográficos distintos. Como exemplo da obtenção digital de informações do modelado superficial, a identificação de unidades de relevo vem sendo desenvolvida em ambiente computacional, amenizando a demanda de trabalho manual e sua subjetividade (GILES e FRANKLIN, 1998).

Segundo BIRKELAND (1984), a distribuição dos solos na paisagem reflete a influência dos vários fatores de formação e está relacionada com combinações entre condições microclimáticas, pedogênese, relevo e processos geológicos superficiais. As formas do relevo, por exercerem influência no fluxo da água, energia e nos processos de redistribuição de material nas vertentes, que controlam sobremaneira esta distribuição. Também GOBIN et al. (2001) afirmam que o movimento da água nas paisagens é o principal responsável pelo processo de desenvolvimento do solo. Por isso, compreender as formas do relevo permite fazer inferências e predições sobre os atributos do solo em diferentes segmentos de vertentes.

As características do relevo estão diretamente relacionadas com os processos de formação do solo e possuem um grande potencial para serem utilizadas na elaboração de levantamentos de solos (KLINGEBIEL et al.,1987). Estas podem ser divididas em atributos primários ou secundários. Os primários são diretamente calculados a partir do Modelo Digital de Elevação (MDE) e inclui variáveis como declividade, orientação das vertentes, elevação, plano e perfil de curvatura, comprimento do caminho do fluxo e área específica de contribuição. Os secundários incluem índice de umidade, índice de transporte de sedimentos e outros (MOORE et al., 1993). Dentre estes atributos a elevação, declividade e orientação, têm sido reconhecidos como os mais efetivos para a realização de levantamentos de solos de média escala (CHAGAS, 2006).

Para definir unidades básicas para o mapeamento geomorfológico e pedológico DIKAU (1989) demonstrou como a análise digital do terreno poderia ser aplicada na quantificação do relevo. Os principais atributos de relevo utilizados para definir estas unidades de relevo foram declividade, plano e perfil de curvatura. Esta abordagem fornece uma base sistemática para derivação de complexas unidades de relevo que podem ser utilizadas para auxiliar na estratificação de atributos do solo.
ODEH et al. (1991) destacaram a importância do delineamento de unidades de paisagem para a projeção dos padrões de amostragem nos levantamentos de solos, com o objetivo de diminuir o erro por extrapolação e, portanto, a classificação equivocada dos solos. Encontraram que a declividade e a curvatura explicam grande parte da variabilidade dos solos da área estudada. O uso da declividade, da orientação e da elevação nos levantamentos de solos é praticamente generalizado. MCBRATNEY et al. (2003) usaram a informação topográfica para o zoneamento de uma região com o objetivo de melhorar a representação de atributos do solo mapeados geoestatisticamente.

Classificando formas de relevo (geoformas) em correspondência com os tipos de solos (pedoformas) numa microbacia no município de Viçosa, IPPOLITI et al. (2005) encontraram que a declividade e o perfil topográfico foram os principais fatores de relevo que influenciaram na distribuição dos solos na região estudada.

Considerando que os solos refletem, em geral, a contribuição das litologias subjacentes e da geomorfologia, objetiva-se nesse trabalho demonstrar a influência dos atributos do relevo derivados de MDE e da geologia na distribuição dos solos na paisagem.

\section{MATERIAL E MÉTODOS}

O presente estudo foi desenvolvido numa área de 303,4 ha, situado na bacia hidrográfica do rio Canguiri, localizada entre as coordenadas UTM de 687254 a 689397 e 7191261 a 7189369 , fuso 22 sul (Figura 01).

Situa-se sobre a Bacia Sedimentar de Curitiba, que segundo SALAMUNI et al. (1999), é composta por diversas unidades geológicas e os sedimentos são depositados, em discordância erosiva, diretamente sobre as rochas do embasamento.

O mapa geológico da área estudada na escala 1:20000, foi adaptado de SALAMUNI et al. (1999), onde foram representadas as unidades geológicas da área, compostas da Formação Guabirotuba, com aluviões e depósitos coluvionares secundários.

As informações de referência foram extraídas de carta topográfica da Coordenação da Região Metropolitana de Curitiba (COMEC), na escala 1:10000 e incluíram as curvas de nível com eqüidistância vertical de 5 metros, pontos cotados e a rede de drenagem. As bases de dados foram geradas no programa computacional ARCVIEW versão 3.2. As informações pedológicas utilizadas no presente trabalho foram modificadas de SUGAMOSTO (2002), escala 1:10000, segundo a classificação da EMBRAPA (1999).

As representações do relevo utilizadas neste estudo foram obtidas a partir de um MDE, que segundo MONTGOMERY (2003), é uma representação espacial da superfície a partir de 
pontos que descrevem a elevação tridimensional de uma grade de dados a intervalos regulares ou irregulares. Seu processo de elaboração foi dividido em três etapas: aquisição dos dados planialtimétricos secundários, geração da grade triangular e elaboração dos atributos do relevo.
Os atributos do relevo obtidos a partir do MDE utilizados no presente trabalho na avaliação da relação com os solos são: elevação, declividade, orientação, plano e perfil de curvatura, radiação solar global e índice topográfico de umidade.

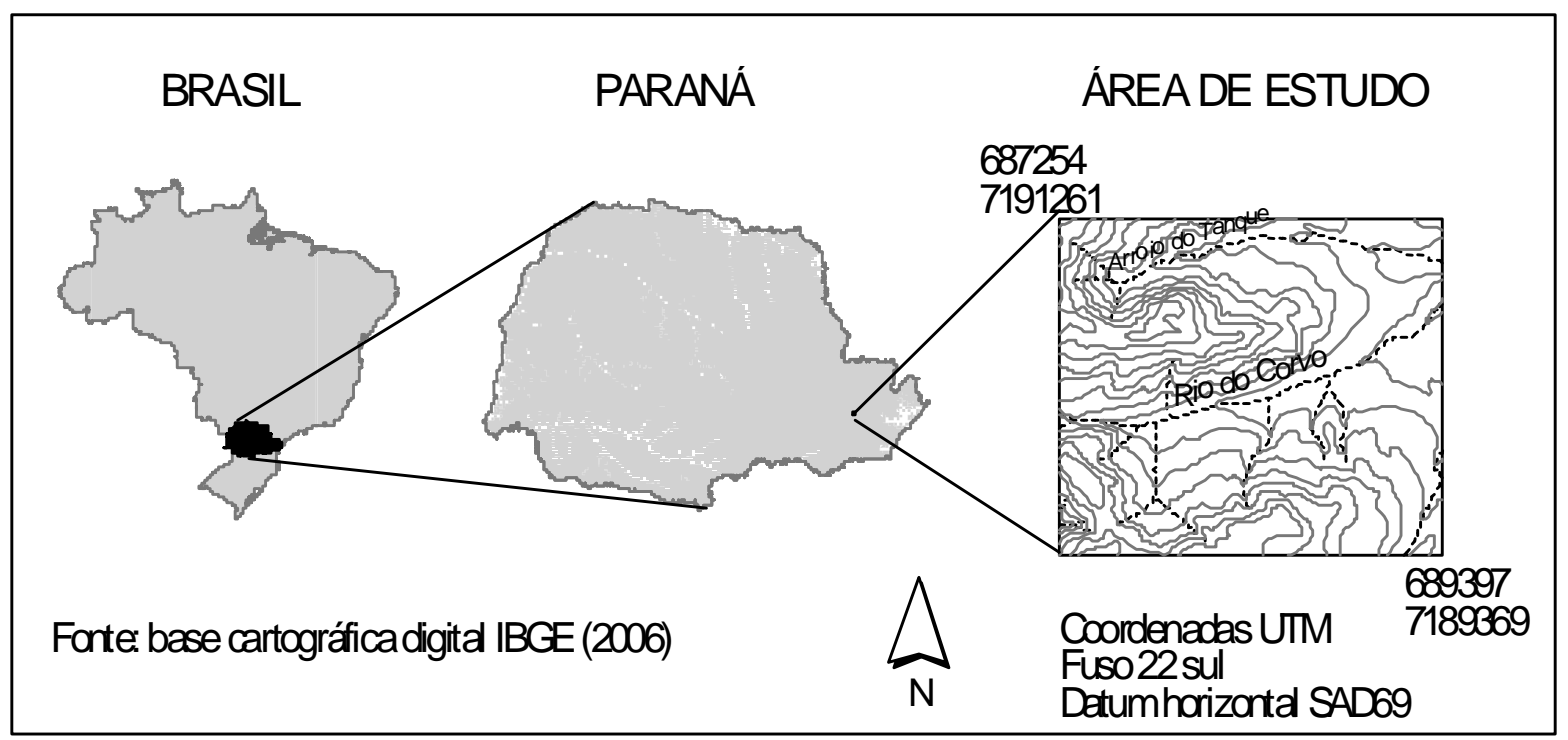

FIGURA 01 - Localização da área de estudo

A declividade é definida por BURROUGH (1986) como sendo um plano tangente a superfície, expresso como a mudança de elevação sobre certa distância, representada no formato digital na resolução de uma grade regular, adotada de $5 \mathrm{~m}$ para a área de estudo.

A orientação das vertentes, segundo CHAGAS (2006), é um atributo primário de relevo pouco explorado no estudo das relações solo paisagem no Brasil, talvez devido à dificuldade de obtenção pelo método tradicional da fotointerpretação. Ela está relacionada diretamente com aspectos importantes como evapotranspiração, insolação, teor de água no solo e conseqüentemente com os atributos do solo e potencial agrícola (MOORE et al., 1993).

O plano de curvatura e o perfil de curvatura representam as formas do relevo, sendo importantes atributos na distinção de unidades geomorfológicas. O primeiro se refere à forma da vertente, analisada em perfil, podendo ser convexa, côncava ou retilínea e o segundo à forma da vertente, em plano, podendo ser convergente, divergente e planar.

A elevação apresenta a distribuição das classes de altitudes, ou dos patamares hipsométricos, em intervalos verticais eqüidistantes.

O índice topográfico de umidade (TWI) tem sido usado para caracterizar a distribuição espacial de zonas de saturação superficial e conteúdo de água nas paisagens. Sua aplicação é para a separação dos solos com caráter hidromórfico, que ocorrem em relevo plano, de outras classes de solos que ocorrem em área planas e suave onduladas. 0 TWI é definido como uma função da declividade e da área de contribuição por unidade de largura ortogonal à direção do fluxo. Em estudo realizado em uma toposseqüência no Colorado, MOORE et al. (1993) verificaram que o TWI e a declividade foram os atributos do relevo que mais se correlacionaram com os atributos medidos no solo. Tal índice é obtido conforme a equação:

$$
T W I=\ln (A s / \tan \beta)
$$

Onde: As é a área de contribuição x tamanho da célula do grid em $\mathrm{m}^{2}$; $\beta$ é a declividade expressa em radianos.

A radiação solar é fonte primária para processos físicos e biológicos que ocorrem no planeta. No hemisfério sul as encostas orientadas para o norte são tradicionalmente reconhecidas como superfícies de radiação mais elevada. Neste trabalho a radiação solar global foi calculada usando métodos descritos por McCUNE e KEON (2002).

\section{RESULTADOS E DISCUSSÃO}

A partir da verificação das relações existentes entre material de origem, solos e atributos do relevo derivados do MDE foram identificadas as diferentes condições que ajudam a compreender a distribuição dos solos na paisagem com distintas características.

As amplitudes de altitude na área de estudo variam de 895 a $951 \mathrm{~m}$, com média de $922 \mathrm{~m}$. As menores altitudes estão localizadas a leste e no centro da área. As maiores, a noroeste, sul e sudoeste. O relevo apresenta predomínio de interflúvios suavemente ondulados e intercalados 
por vales de fundo chato amplo, bem como pequenas variações locais para um relevo ondulado na porção central e noroeste, onde o trabalho de dissecação produzido por cursos fluviais menores resultou na conformação de pequenas ombreiras. A variação altimétrica é pequena, sendo que $50 \%$ da área apresenta altitude entre 905 e $923 \mathrm{~m}$. As altitudes inferiores a $904 \mathrm{~m}$ representam $16 \%$ da área, enquanto que as superiores a $924 \mathrm{~m}$ representam 34\% (Figura 02).
A declividade é considerada um dos mais importantes atributos topográficos primários que controlam os processos pedogenéticos, segundo GALLANT e WILSON (2000), ela afeta diretamente a velocidade do fluxo superficial e subsuperficial de água e conseqüentemente o teor de água no solo, o potencial de erosão/deposição e muitos outros processos importantes na formação dos solos.

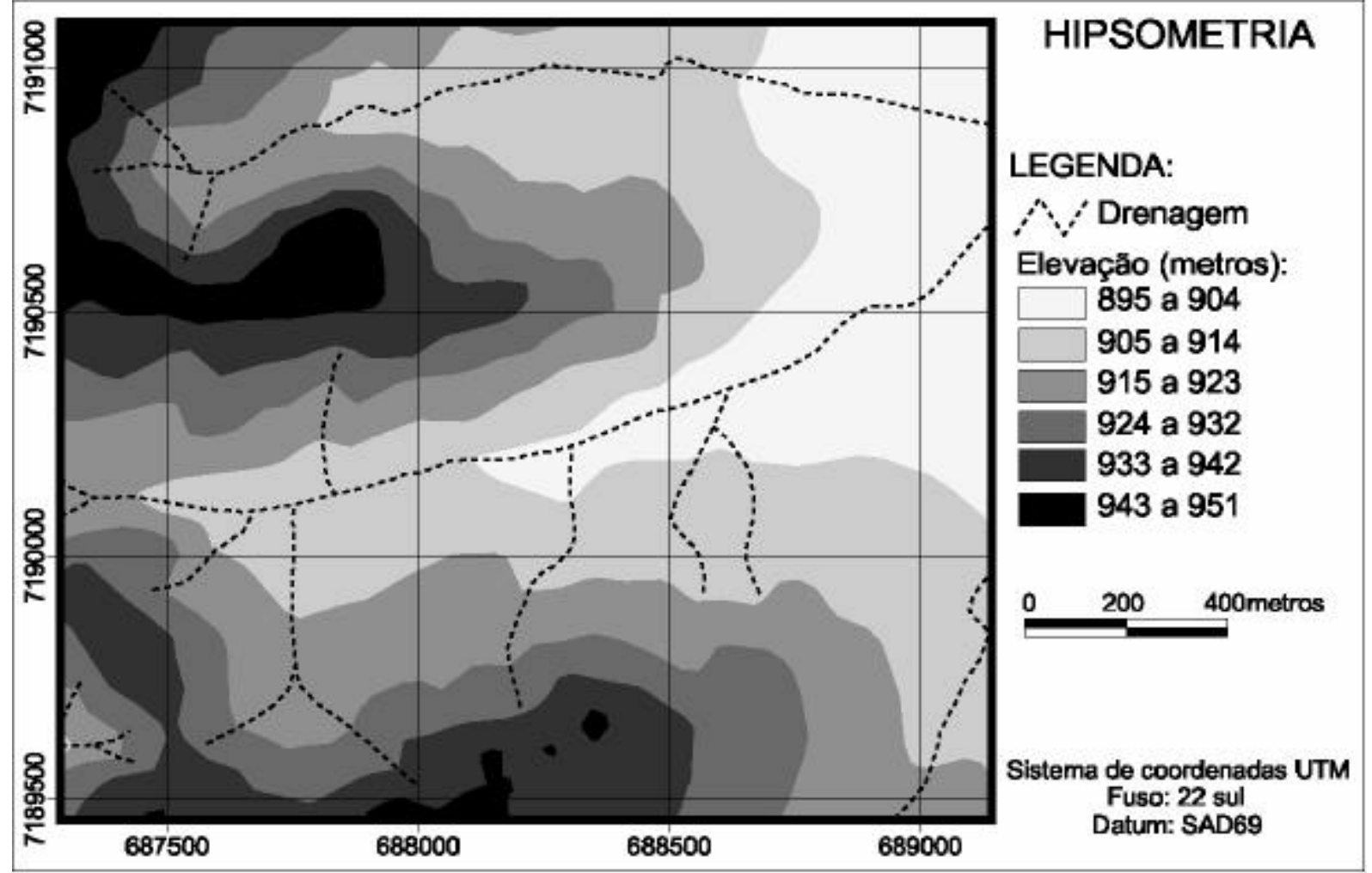

FIGURA 02 - Mapa Hipsométrico

$\mathrm{Na}$ área estudada os maiores declives estão associados sempre com o Terciário (médio a superior) Mioceno a Plioceno e ao Quaternário (inferior) Pleistoceno, da unidade geológica da Formação Guabirotuba (Figura 03). Esses declives representam $33 \%$ da área com inclinações superiores a $8 \%$ e inferior a $45 \%$, respectivamente relevo ondulado e forte ondulado. Os menores declives estão associados às áreas com idade do Quaternário (superior) Holoceno, da unidade geológica de Aluviões e depósitos coluvionares secundários. As menores declividades entre 0 e $8 \%$ representam $67 \%$ da área, sendo distribuídas em relevo plano e suave ondulado (Figura 04).

Os solos identificados (Figura 05) com caráter hidromórfico (associação de Gleissolos e Organossolos) somam 54,21 ha, estando $96 \%$ localizados nas porções de baixas altitudes, onde 0 relevo varia de plano a suave ondulado, com declividade inferior a $8 \%$. 


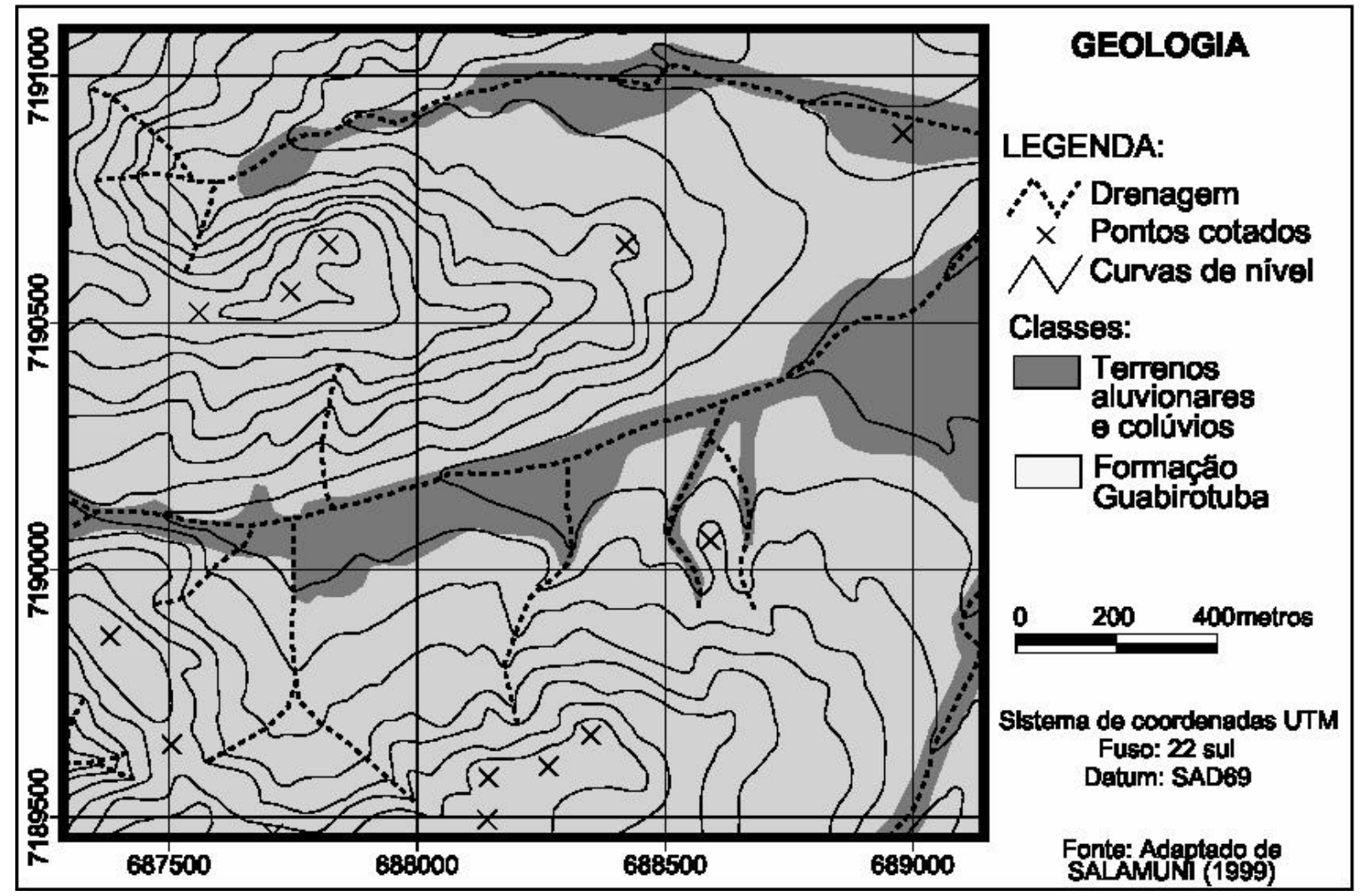

FIGURA 03 - Mapa Geológico

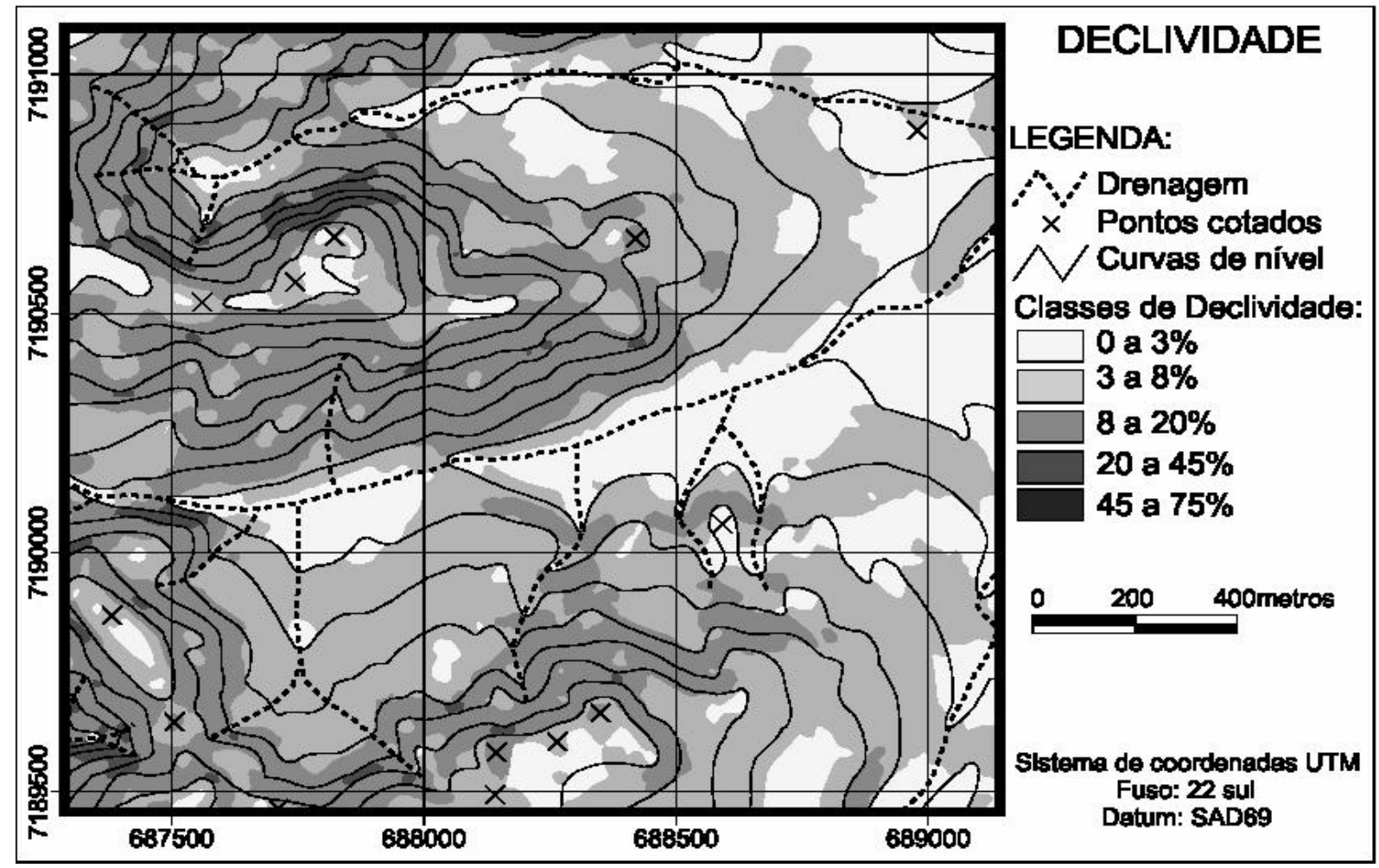

FIGURA 04 - Mapa de Declividade 


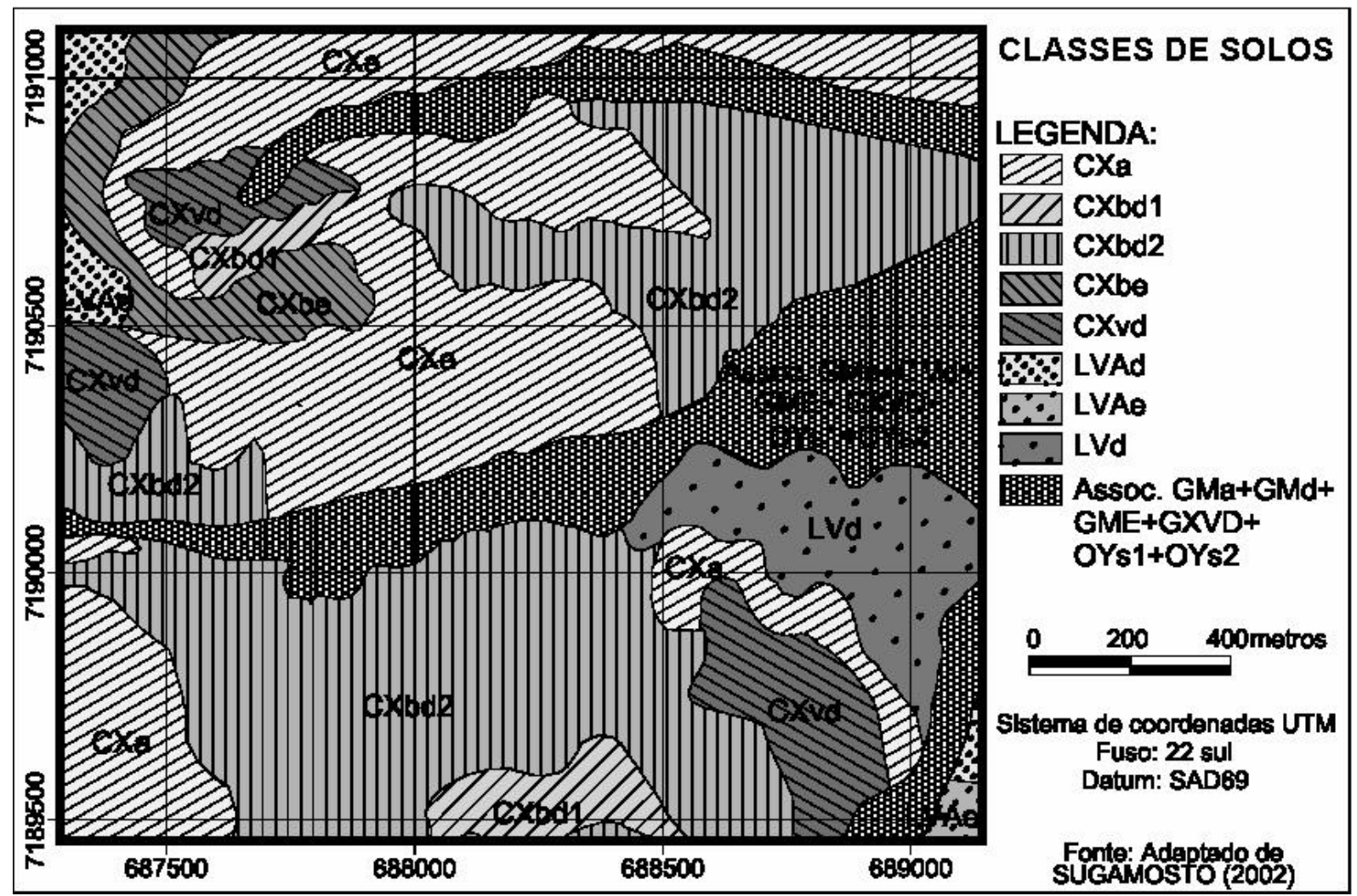

FIGURA 05 - Mapa de Solos adaptado de SUGAMOSTO (2002)

Sobre a unidade geológica Aluviões e depósitos coluvionares secundários localizam-se solos com caráter hidromórfico e os outros solos estão sobre a Formação Guabirotuba.

Os Cambissolos estão predominantemente associados a maiores declividades e posições hipsométricas intermediárias, enquanto os Latossolos ocorrem preferencialmente associados a menores declividades e áreas aplainadas nas porções mais elevadas, quando associados a colúvios ocorrem nas posições mais baixas. Os solos de caráter hidromórficos ocorrem exclusivamente nas posições hipsométricas inferiores e com baixa declividade.

Nas unidades mapeadas o Cambissolo Háplico Alumínico típico ( $\mathrm{CXa}$ ) aparece predominantemente em declividades de 8 a $20 \%$ e na classe hipsométrica de 904 a $923 \mathrm{~m}$ de altitude. O Cambissolo Háplico Tb Distrófico típico (CXbd1) predomina em declividades de 3 a $8 \%$ e hipsométria de 932 a 942 m. O Cambissolo Háplico Tb Distrófico latossólico (CXbd2) encontra-se predominantemente na declividade de 3 a $8 \% \mathrm{com}$ valores hipsométricos entre 904 a $932 \mathrm{~m}$. O Cambissolo Háplico Tb Eutrófico típico (CXbe) predomina nas declividades de 3 a $8 \%$ e situa-se nas elevações entre 932 a $951 \mathrm{~m}$. O Cambissolo Háplico Ta Distrófico típico (CXvd) predomina nas declividade de 3 a $8 \%$ e na classe hipsométrica de 914 a $932 \mathrm{~m}$. Enquanto que o Latossolo VermelhoAmarelho Distrófico típico (LVAd) apresenta-se predominantemente no intervalos entre as declividade de 3 a $8 \%$ com valores hipsométricos de 942 a $951 \mathrm{~m}$. O Latossolo Vermelho-Amarelo Eutrófico câmbico (LVAe) situa-se predominantemente em declividade inferior a $3 \%$ e elevação entre 914 a $923 \mathrm{~m}$. O Latossolo Vermelho Distrófico típico ( $L V d)$ predomina em declividade inferiores a $8 \%$ e possui valores hipsométricos entre 904 a 914 m (Tabela 01 e 02). 
TABELA 01 - Relação das classes de atributos do relevo e de índices derivados com as unidades de mapeamento de solos.

\begin{tabular}{|c|c|c|c|c|c|c|c|c|c|c|}
\hline \multirow{2}{*}{\multicolumn{2}{|c|}{$\begin{array}{l}\text { Atributos do relevo e índices } \\
\text { derivados }\end{array}$}} & \multicolumn{9}{|c|}{$\begin{array}{l}\text { Percentual de ocorrência da classe de relevo e de índices derivados na área da } \\
\text { unidades de mapeamento de solos }\end{array}$} \\
\hline & & \multirow{3}{*}{$\begin{array}{c}\begin{array}{c}\text { CXa } \\
(\%)\end{array} \\
7\end{array}$} & \multirow{3}{*}{$\begin{array}{c}\text { CXbd1 } \\
(\%)\end{array}$} & \multirow{3}{*}{$\begin{array}{c}\begin{array}{c}\text { CXbd2 } \\
(\%)\end{array} \\
12\end{array}$} & \multirow{3}{*}{$\begin{array}{c}\begin{array}{c}\text { CXbe } \\
(\%)\end{array} \\
0\end{array}$} & \multirow{3}{*}{$\begin{array}{c}\begin{array}{c}\text { CXvd } \\
(\%)\end{array} \\
0\end{array}$} & \multirow{3}{*}{$\begin{array}{c}\text { LVAd } \\
(\%) \\
0\end{array}$} & \multirow{3}{*}{$\begin{array}{c}\text { LVAe } \\
(\%) \\
0\end{array}$} & \multirow{3}{*}{$\begin{array}{l}\begin{array}{l}\text { LVd } \\
(\%)\end{array} \\
14\end{array}$} & \multirow{3}{*}{$\begin{array}{c}\begin{array}{c}\text { Associação } \\
\text { OY+GM+GX } \\
(\%)\end{array} \\
54\end{array}$} \\
\hline & & & & & & & & & & \\
\hline Elevação & 895 a 904 & & & & & & & & & \\
\hline$(\mathrm{m})$ & 905 a 914 & 26 & 0 & 22 & 0 & 4 & 13 & 3 & 86 & 39 \\
\hline & 915 a 923 & 24 & 0 & 33 & 0 & 58 & 0 & 97 & 0 & 7 \\
\hline & 924 a 932 & 21 & 12 & 23 & 0 & 28 & 0 & 0 & 0 & 0 \\
\hline & 933 а 942 & 20 & 74 & 9 & 40 & 10 & 2 & 0 & 0 & 0 \\
\hline & 943 a 951 & 1 & 14 & 1 & 60 & 0 & 85 & 0 & 0 & 0 \\
\hline \multirow[t]{5}{*}{ Declividade } & 0 a $3 \%$ & 67 & 14 & 12 & 13 & 9 & 32 & 63 & 47 & 67 \\
\hline & 3 a $8 \%$ & 29 & 32 & 58 & 29 & 52 & 44 & 37 & 49 & 29 \\
\hline & 8 a $20 \%$ & 2 & 52 & 30 & 57 & 36 & 23 & 0 & 4 & 2 \\
\hline & 20 a $45 \%$ & 1 & 2 & 1 & 0 & 2 & 0 & 0 & 0 & $\overline{1}$ \\
\hline & 45 a $75 \%$ & 0 & 0 & 0 & 0 & 0 & 0 & 0 & 0 & 0 \\
\hline \multirow[t]{4}{*}{ Orientação } & Leste & 20 & 22 & 32 & 38 & 40 & 30 & 51 & 35 & 25 \\
\hline & Norte & 31 & 46 & 54 & 21 & 34 & 30 & 48 & 64 & 66 \\
\hline & Oeste & 7 & 8 & 5 & 7 & 2 & 1 & 1 & 2 & 2 \\
\hline & Sul & 42 & 23 & 10 & 34 & 24 & 39 & 0 & 0 & 7 \\
\hline Plano de & Convergente & 40 & 48 & 42 & 45 & 35 & 43 & 28 & 18 & 48 \\
\hline \multirow[t]{2}{*}{ Curvatura } & Planar & 12 & 2 & 13 & 7 & 12 & 16 & 72 & 27 & 40 \\
\hline & Divergente & 48 & 50 & 45 & 48 & 52 & 41 & 0 & 55 & 12 \\
\hline Perfil de & Côncavo & 50 & 36 & 54 & 29 & 55 & 12 & 36 & 43 & 53 \\
\hline \multirow[t]{2}{*}{ Curvatura } & Retilíneo & 43 & 58 & 35 & 71 & 38 & 80 & 64 & 34 & 15 \\
\hline & Convexo & 6 & 6 & 10 & 0 & 7 & 8 & 0 & 23 & 32 \\
\hline Índice de & $<11$ & 84 & 96 & 78 & 96 & 86 & 92 & 69 & 71 & 29 \\
\hline Umidade & $>11$ & 16 & 4 & 22 & 4 & 14 & 8 & 31 & 29 & 71 \\
\hline \multicolumn{11}{|l|}{ Radiação } \\
\hline Solar & $<96$ & 40 & 52 & 7 & 35 & 23 & 31 & 80 & 34 & 3 \\
\hline $\mathrm{MJ} \mathrm{\textrm {cm } ^ { - 2 }}$ & 0,97 a 1,00 & 27 & 48 & 26 & 37 & 25 & 45 & 20 & 66 & 65 \\
\hline$a^{-1}$ & $>1,00$ & 33 & 0 & 67 & 28 & 52 & 24 & 0 & 0 & 32 \\
\hline
\end{tabular}

TABELA 02 - Unidades de solos, geologia e atributos do relevo e índices derivados predominantes.

\begin{tabular}{|c|c|c|c|c|c|c|c|c|}
\hline $\begin{array}{l}\text { Unidade de } \\
\text { mapeamento }\end{array}$ & $\begin{array}{c}\text { Declividade } \\
\%\end{array}$ & $\begin{array}{c}\text { Elevação } \\
\text { m }\end{array}$ & Orientação & Geologia & $\begin{array}{c}\text { Plano } \\
\text { curvatura }\end{array}$ & $\begin{array}{c}\text { Perfil } \\
\text { curvatura }\end{array}$ & $\begin{array}{c}\text { Radiação } \\
\text { global } \\
\mathrm{MJ} \mathrm{cm}^{-2} \\
\text { ano }^{-1}\end{array}$ & TM \\
\hline $\begin{array}{l}\text { Associação: } \\
\text { OY+GM+GX }\end{array}$ & $<3$ & $895-914$ & $\mathrm{~L}$ & ADCS & conv.ppla & côn/.ret. & $0,96-1,11$ & $>11$ \\
\hline CXa & 8-20 & $904-923$ & $S$ & G & diver./conv. & côn./convex & 0,65-096 & $<11$ \\
\hline CXbd1 & $3-8$ & $932-942$ & $\mathrm{~N}$ & $\mathrm{G}$ & conv./diver. & convex. & $0,96-1,00$ & $<11$ \\
\hline CXbd2 & $3-8$ & 904-932 & $\mathrm{N}$ & $G$ & conv./diver. & côn. & $1,00-1,11$ & $<11$ \\
\hline CXbe & 8-20 & $932-951$ & LS & G & conv/diver. & convex. & $0,65-1,00$ & $<11$ \\
\hline CXVd & $3-8$ & $914-932$ & L/N & G & diver./conv. & côn. & $1,00-1,11$ & $<11$ \\
\hline LVAd & $3-8$ & $942-951$ & $S$ & G & conv./diver. & convex. & $0,96-1,00$ & $<11$ \\
\hline LVAe & $<3$ & $914-923$ & L/N & G & diver. & convex. & $0,96-1,00$ & $<11$ \\
\hline LVd & $<8$ & $904-914$ & $\mathrm{~N}$ & G & diver. & côn./convex & $1,00-1,11$ & $<11$ \\
\hline
\end{tabular}

conv.= convergente, diver.=divergente, pla.=planar, côn.= côncavo, convx.=convexo, ret.=retilíneo, G = Formação Guabirotuba, ADCS= Aluviões e depósitos coluvionares secundários, N=norte, $\mathrm{S}=$ sul, L=leste. 
O plano de curvatura se refere ao caráter divergente ou convergente dos fluxos de matéria e energia nas vertentes, em projeção horizontal. As áreas convergentes representam os vales e as divergentes os interflúvios. A curvatura horizontal está relacionada aos processos de migração e acúmulo de água, minerais e matéria orgânica no solo através da superfície e subsuperfície, proporcionados pela gravidade, desempenhando importante papel sobre o balanço hídrico e os processos de pedogênese (VALERIANO e CARVALHO JÚNIOR, 2003). Na área de estudo, os resultados obtidos mostram que $41 \%$ das vertentes são convexas, $41 \%$ são côncavas e $18 \%$ são planares (Figura 06).

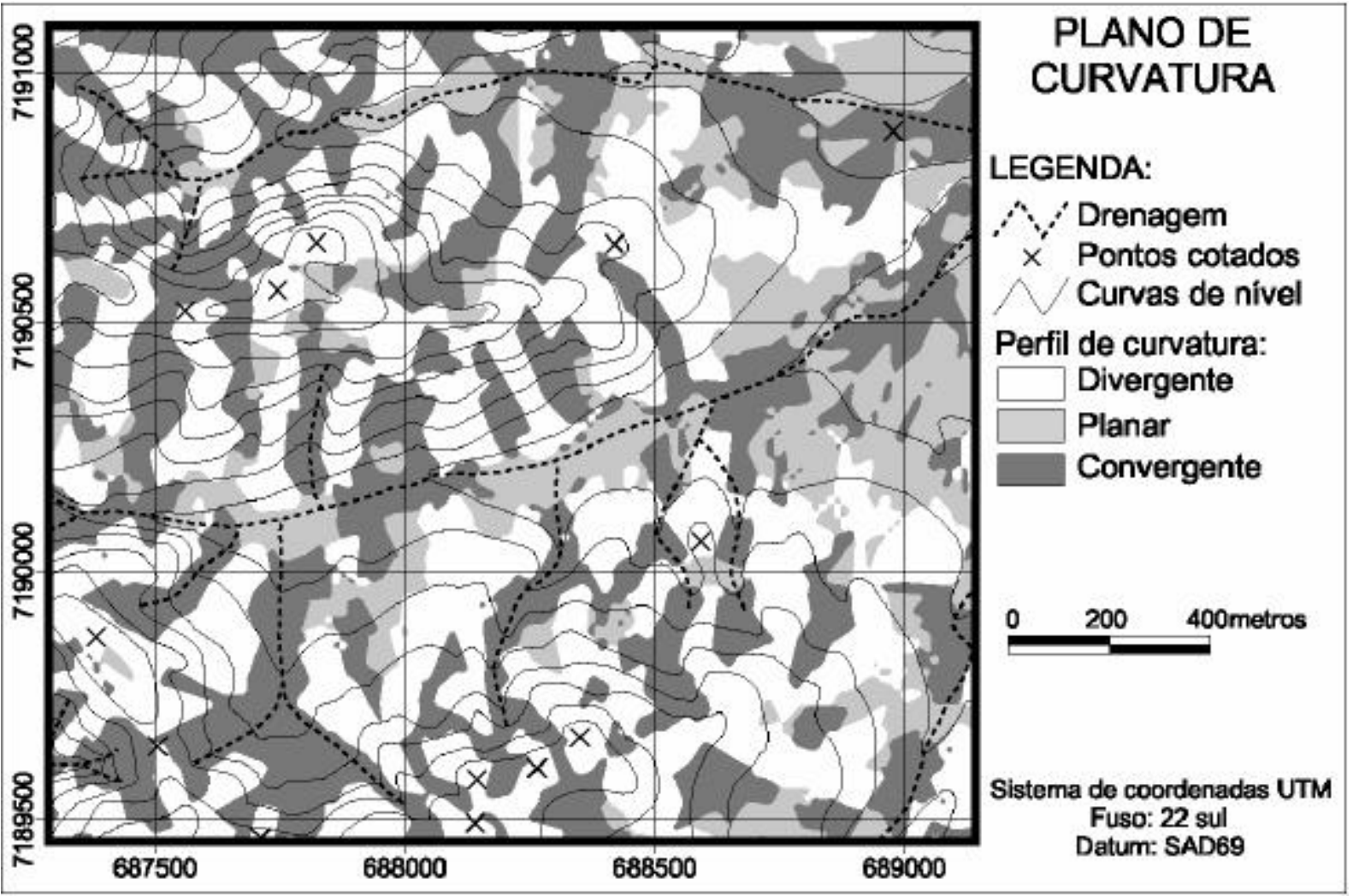

FIGURA 06 - Mapa do Plano de Curvatura das Vertentes

Verificaram-se relações entre a curvatura horizontal e a espessura dos solos, pois de acordo com HALL e OLSON (1991) a força erosiva causada pela concentração de água nas encostas côncavas é considerável e, a remoção do material do solo pode ser bastante expressiva, ocorrendo com tanta intensidade que promove um constante rejuvenescimento dos solos. Como regra geral, na área estudada, os solos mais profundos e mais evoluídos ocupam encostas divergentes e planares, enquanto os menos evoluídos e mais rasos (câmbicos) tendem a ocorrer em encostas convergentes. A ocorrência de solos mais rasos nestas condições está relacionada, juntamente com a declividade, com o maior fluxo convergente de água nestas áreas, que favorece a morfogênese, levando estes solos a um constante rejuvenescimento por erosão (CHAGAS, 2006).

Embora a relação da curvatura horizontal com os solos não se apresente tão explícita no trabalho, fato justificado pela escala do mapeamento de solos 1:10000 não contemplar o detalhamento obtido no mapa de plano de curvatura, evidencia-se nas Tabelas 1 e 2 que os Cambissolos apresentaram-se nos planos de curvatura horizontal convergente e divergente e os Latossolos, preferencialmente nos divergentes, enquanto a associação Gleissolos e Organossolos em convergentes e planares. As unidades pedológicas CXa, CXbd1, CXbd2, CXbe, CXvd e LVAd apresentaram predomínio nos planos de curvatura convergente e divergente, as unidades LVAe e LVd divergente e a associação Gleissolos e Organossolos apresentam-se nos planos de curvatura convergente e planar.

O perfil de curvatura (ou curvatura vertical) se refere à forma da vertente, podendo ser convexa, côncava ou retilínea, ao ser analisada em perfil. Esta variável está relacionada aos processos de migração e acúmulo de água, minerais e matéria orgânica no solo através da superfície, proporcionados pela gravidade. Associada à orientação de vertentes, o perfil de curvatura desempenha também importante papel sobre a 
evapotranspiração e o balanço hídrico (VALERIANO, 2003).

As formas de perfil e plano de curvatura de uma encosta podem influenciar grandemente na distribuição lateral dos processos pedológicos, hidrológicos e geomorfológicos e, por conseguinte, os solos que resultam das interações entre esses processos (PENNOCK et al., 1987). Essa influência, segundo CHAGAS (2006), tem sido relacionada, principalmente, ao controle que as formas côncavas e convexas exercem sobre a distribuição de águas e materiais solúveis das partes mais elevadas para as mais baixas.

Os resultados obtidos para o perfil da curvatura mostram que as encostas côncavas predominam com $50 \%$, as convexas com $37 \%$ e as retilíneas com 13\% (Figura 07).

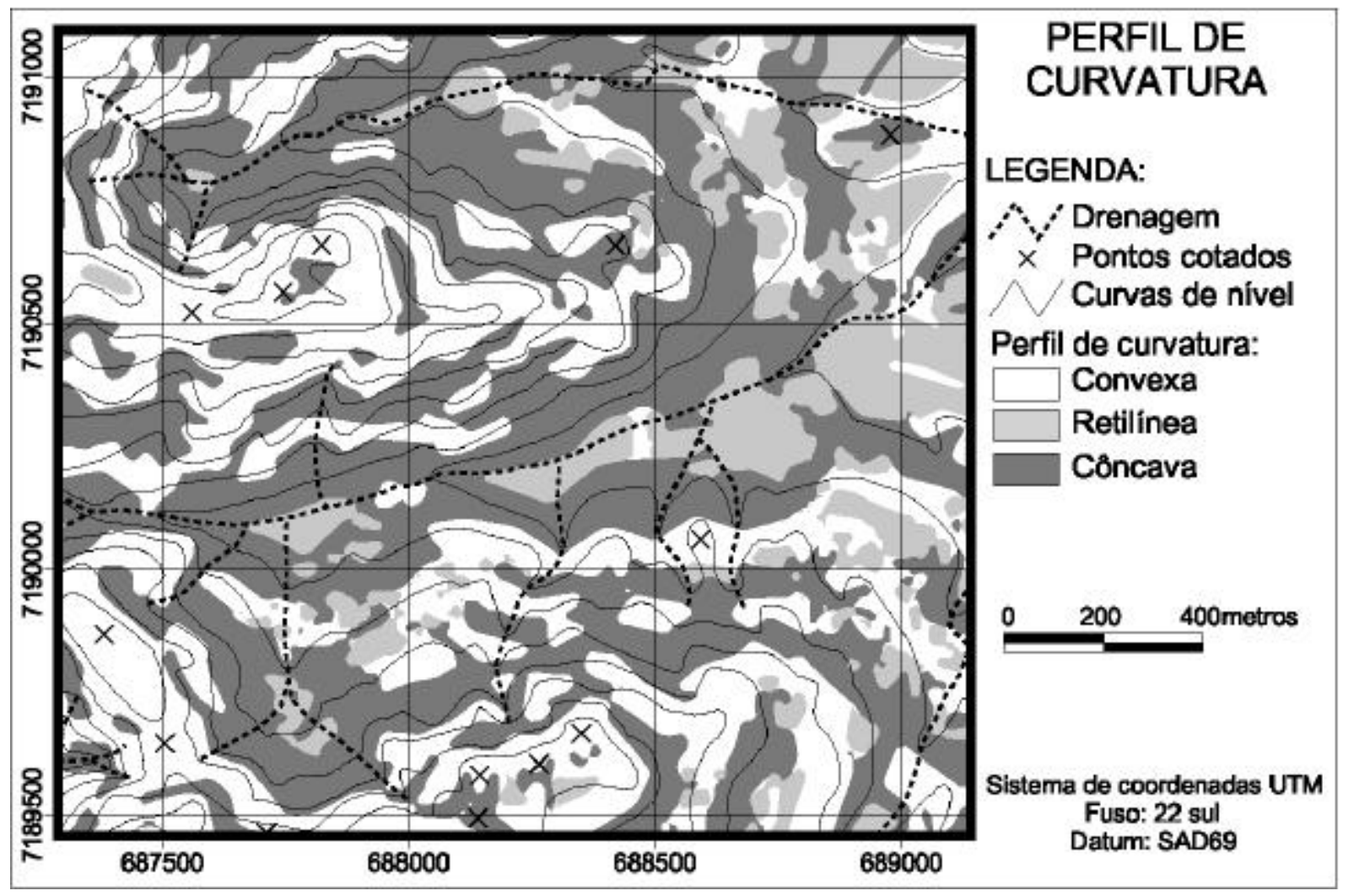

FIGURA 07 - Mapa do Perfil de Curvatura das Vertentes

Nas Tabelas 1 e 2 constata-se que os Cambissolos se encontram predominantemente em perfis de curvatura côncavos e convexos, os Latossolos preferencialmente convexos e a associação Gleissolos e Organossolos côncavos e retilíneos. As unidades pedológicas $\mathrm{CXa}$ apresentam perfil côncavo e convexo, CXbd1 e CXbe perfil convexo, CXbd2 e CXvd perfil côncavo, LVAd e LVAe perfil convexo e LVd perfil côncavo/convexo.

A relação do atributo perfil de curvatura com os solos, também apresentou resultados generalizados pelo mesmo fato justificado no plano de curvatura.

O TWI é muito usado para identificar áreas úmidas (GEISSLER et al.,1995). Na área estudada os valores obtidos para este índice variam de 6,69 a 23,07 , com um valor médio de 14,88 , sendo que $73 \%$ das células têm valor menor que 11 (Figura 08). Esses resultados são semelhantes aos valores encontrados por MOORE et al. (1993) e CHAGAS (2006). Os valores elevados de TWI estão associados a relevo plano e áreas de várzea, onde são encontrados Organossolos e Gleissolos, ou áreas côncavas, que favorecem ao acúmulo de água no solo. Este atributo demonstrou, na unidade dos solos com caráter hidromórfico, $71 \%$ de coincidência com a classe superior a 11. Nas demais unidades pedológicas o predomínio foi na classe inferior a 11 (Tabelas 1 e 2). A unidade de mapeamento associação Gleissolos e Organossolos apresentou estreita relação com o de índice de umidade, uma 
vez que $71 \%$ desses solos estão contidos no índice superior a 11 . Os $29 \%$ restantes estão nas unidades LVd e CXbd2, que estão na vizinhança com características de relevo semelhantes, porém com litologia distinta, e na LVAe localizada em topos aplainados, onde o índice também apresentou valores elevados;

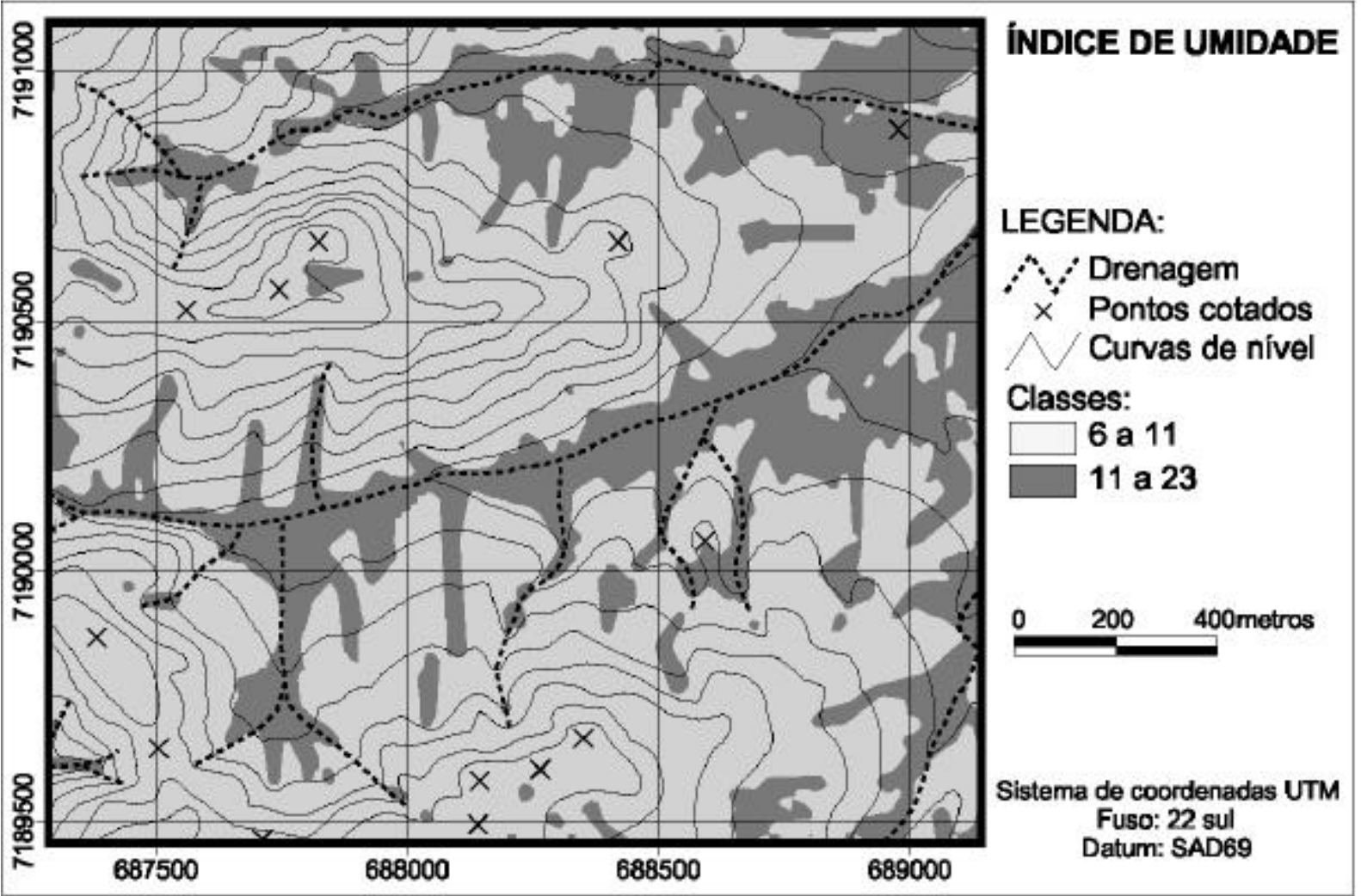

FIGURA 08 - Mapa do Índice de Umidade $(T W I=\ln (A s / \tan \beta))$

Como TWI foi obtido a partir de MDE derivado de mapa planialtimétrico na escala 1:10000, com eqüidistância vertical de $5 \mathrm{~m}$, existem imperfeições em seus resultados oriundos da generalização da eqüidistância vertical dessa escala. Se o mapa de referência apresentasse maior detalhe os limites seriam mais precisos.

O relevo é um dos principais fatores que influencia na distribuição da insolação na paisagem. Assim, a variação na elevação e orientação das vertentes associada à declividade, interfere no sombreamento causado por feições geomorfológicas, resultando em fortes gradientes locais. Tais gradientes causam elevada heterogeneidade espacial e temporal na distribuição da energia e no balanço de água, que influencia no regime de temperatura do ar e do solo, evapotranspiração, umidade do solo e energia disponível para fotossíntese. Com isso, estes fatores, afetam o padrão espacial dos processos naturais, dentre eles a distribuição das propriedades dos solos (FU e RICH, 1999).
O atributo orientação das vertentes foi organizado em quatro classes: norte (NW315으. NE45), leste (NE45-SE135), sul (SE135-SW225) e oeste (SW225-NW315). Os resultados mostraram na área o predomínio das classes norte e leste, respectivamente $47 \%$ e $28 \%$. Estes resultados indicam uma inclinação da área em relação ao nível de base local, localizado a NE. A orientação sul representa $21 \%$ e oeste $4 \%$ (Figura 09 ).

No mapa de radiação solar global obtido (Figura 10) os valores variam de 0,65 a 1,11 MJ $\mathrm{cm}^{-2}$ ano-1, com uma média aproximada de 0,88 MJ $\mathrm{cm}^{-2}$ ano $^{-1}$, sendo que $47 \%$ das células apresentam valores superiores a $1,00 \mathrm{MJ} \mathrm{cm}^{-2} \mathrm{ano}^{-1}$. $\mathrm{Na}$ área, os valores mais elevados são encontrados nas porções mais aplainadas e voltadas para o N/NE e, onde não existe sombreamento do relevo. As regiões de menor radiação global são encontradas nas encostas com declividade elevadas e com suas faces voltadas para o S e SW. 


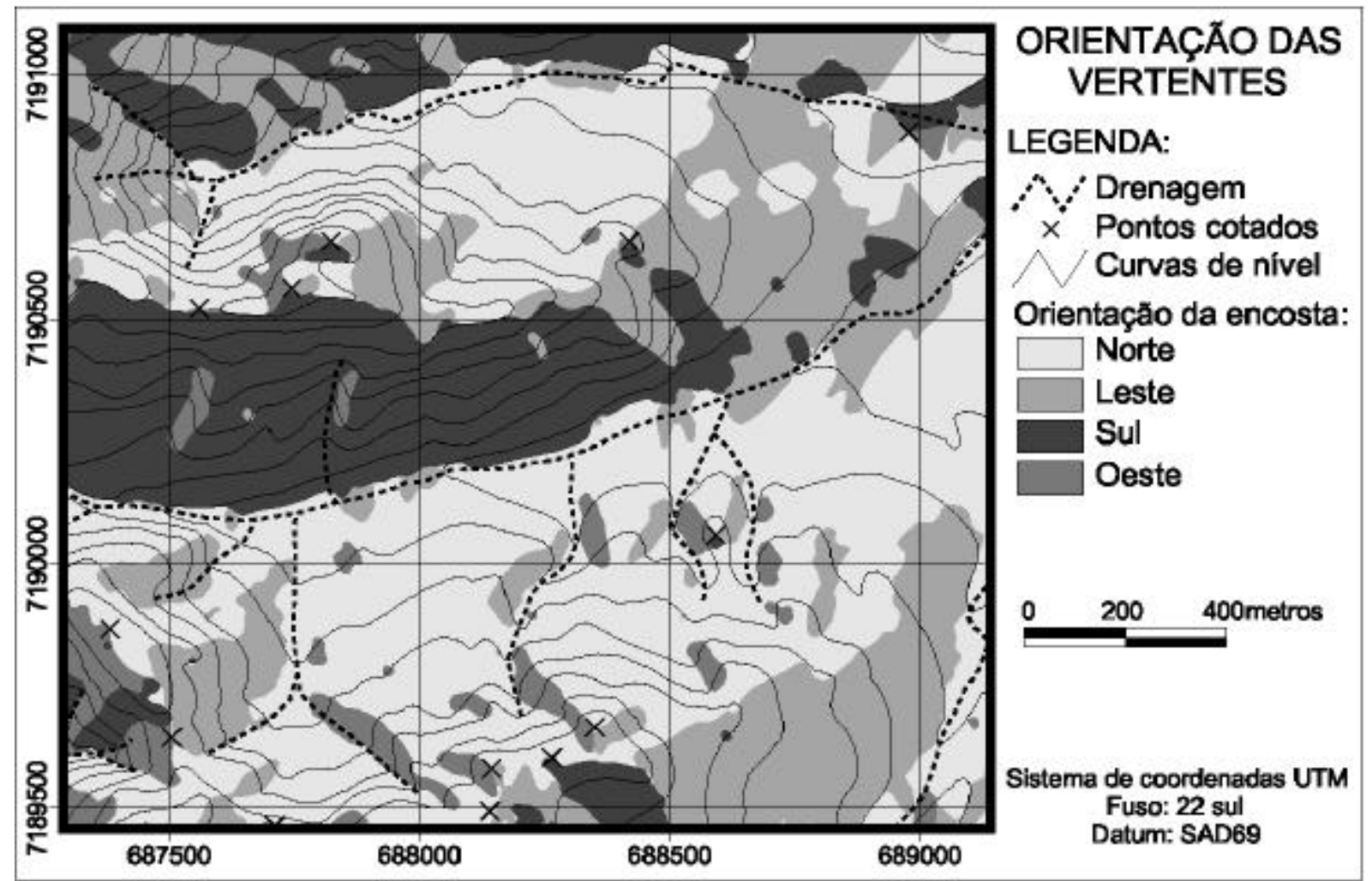

FIGURA 09 - Mapa de Orientação das Vertentes

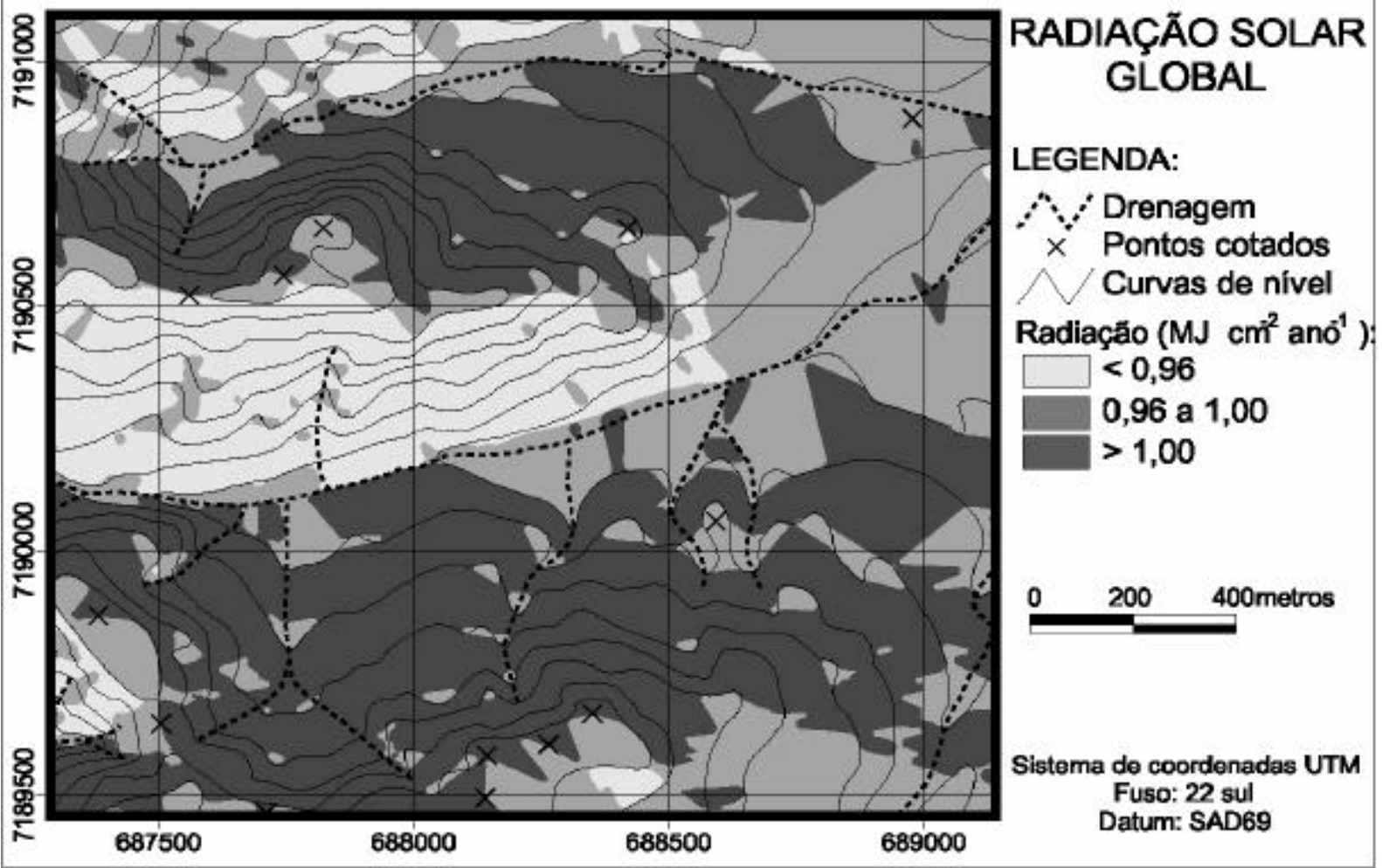

FIGURA 10 - Mapa de Radiação Solar Global 
$\mathrm{Na}$ análise da radiação global que chega às diferentes encostas da área (Tabela 02), as que são voltadas para leste apresentam valores superiores a $0,96 \mathrm{MJ} \mathrm{cm}^{-2}$ ano-1, em $97 \%$ da sua superfície. As encostas voltadas para o norte em $100 \%$ da sua superfície a radiação está acima de $0,96 \mathrm{MJ} \mathrm{cm}^{-2}$ ano-1 $^{-1}$ as voltadas para oeste em $91 \%$ de suas superfícies a radiação está entre os valores acima citados. Todas estas encostas acima apresentam valores mais elevados do que as encostas voltadas para o sul, que apresentam menor radiação solar incidente, pois em $80 \%$ de suas superfícies a radiação é inferior a $0,65 \mathrm{MJ} \mathrm{cm}^{-2} \mathrm{ano}^{-1}$, e os outros $20 \%$ estão entre 0,65 e $1,00 \mathrm{MJ} \mathrm{cm}^{-2}$ ano $^{-1}$.

Apesar dos atributos de orientação das vertentes e a radiação solar terem demonstrado na avaliação algumas limitações na relação de predomínio com as unidades de solos, isso se justifica pelas características do relevo na área de estudo, uma vez que, segundo MITASOVA e HOFIERKA (1993), estes atributos se tornam menos significativos na relação com os solos, quando o gradiente de declividade é pequeno, fato constatado na área.

No entanto, as amostras de campo demonstraram que as vertentes com maiores declividades e orientadas para o sul apresentaram matiz mais amarelada (entre 7,5 YR a $10 \mathrm{YR}$ ), enquanto que as faces que recebem mais radiação solar possuem cor mais avermelhada (entre 2,5 YR a 5 YR), em concordância com CHAGAS (2006).

\section{CONCLUSÕES}

1. O índice de umidade juntamente com a geologia apresentou estreita relação com os solos, sendo que os solos de caráter hidromórfico estão predominantemente nas áreas com TWI superior a 11 e unidades geológicas com idade do Quaternário. As demais unidades encontram-se na classe de TWI inferior a 11 e unidade geológica Formação Guabirotuba;

2. Os Latossolos apresentam respectivamente predominância de plano e perfil de curvatura, divergente e convexa, os Cambissolos convergente/divergente e côncavo e a associação Gleissolos e Organossolos convergente/planar e retilínea;

3. A orientação das vertentes e a radiação solar desempenharam papel limitado com as unidades de mapeamento de solos, não sendo identificada uma relação de predominância desses atributos nas unidades. No entanto, com avaliação de campo se concluiu que as vertentes mais inclinadas com orientação o sul possuem solos com matiz mais amarelado do que as voltadas para leste e norte;

4. A declividade foi o atributo que apresentou melhor relação com as unidades de solos, pois os solos com caráter hidromórfico estão predominantemente em declividade inferior a $3 \%$, os Latossolos em declividades inferiores a $8 \%$ e os Cambissolos se localizam em declividade até $20 \%$; 5. A elevação demonstrou relação com os Latossolos, que estão situados nas posições mais elevadas e preservadas dos processos de entalhamento da paisagem, exceto a unidade Lvd que está em posição mais baixa. Os solos de caráter hidromórfico se localizam nas posições mais baixas e os Cambissolos nas posições intermediárias;

\section{REFERÊNCIAS}

1. BIRKELAND, P. W. Soils and geomorphology. New York: Oxford University Press, 1984. 430 p.

2. BURROUGH, P. A. Principles of geographical information systems of land resources assessment. Francis \& Taylor, 1986. $185 \mathrm{p}$.

3. CHAGAS, C. da S. Mapeamento digital de solos por correlação ambiental e redes neurais em uma bacia hidrográfica no domínio de mar de morros. 223 f. Tese (Doutorado em solos e nutrição de plantas) Universidade Federal de Viçosa, Viçosa, 2006.

4. DIKAU, R. The application of a digital relief model to landform analysis in geomorphology. In: RAPER, J. (Ed.). Three dimensional applications in geographic information systems. New York: Taylor e Francis, 1989. p. 51-77.

5. EMBRAPA. Centro Nacional de Pesquisa em Solos (Rio de Janeiro, RJ). Sistema Brasileiro de Classificação de Solos. Brasília: Embrapa Produção de Informação; Rio de Janeiro: Embrapa Solos, 1999. 412 p.

6. FU, P.; RICH, P. M. Design and Implementation of the Solar Analyst: An ArcView Extension for Modeling Solar Radiation at Landscape Scales. IN: ESRI, International User Conference Proceedings. San Diego, ESRI, 1999.

7. GALLANT, J. C.; WILSON, J. P. Primary topographic attributes. In: WILSON, J. P.; GALLANT, J. C. (Eds.). Terrain Analysis: Principles and applications. New York: John Wiley, 2000. p. 51-85.

8. GEISSLER, P. E. I. D.; MOORE, N. J.; MCKENZIE, P. J. RYAN. Soil landscape modeling and spatial prediction of soil attributes. International Journal of Geographic Information System, v. 9, n. 4, p. 421- 432, 1995.

9. GILES, P. T.; FRANKLIN, S. E. An automated approach to the classification of the slope units using digital data. Geomorphology, v. 21, p. 251-264. 1998.

10. GOBIN, A.; CAMPLING, P.; FEYEN, J. Soil-landscape modelling to quantify spatial variability of soil texture. Physics and Chemistry of the Earth, v. 26, p. 41-45, 2001. 
11. HALL, G. F.; OLSON, C. G. Predicting variability of soils from landscape models. In: MAUSBACH, M. J.; WILDING, L. P. (Eds.). Spatial variabilities of soils and landforms. Madison, Wisconsin: Soil Science Society of America, 1991. p. 9-24. (SSSA Special Publication; n. 28).

12. HUDSON, B. D. The soil survey as a paradigm-based science. Soil Science Society of America Journal, v. 56, p. 836-841, 1992.

13. IPPOLITI, R. G. A.; COSTA, L. M.; SCHAEFER, C. E. G. R.; FILHO, E.I.F.; GAGGERO, M. R.; SOUZA, E., Análise digital de terreno: Ferramenta na identificação de pedoformas em microbacia na região de "mar de morros" (MG). Revista Brasileira de Ciência do Solo, v. 29, n. 2, p. 269-276, 2005.

14. KLINGEBIEL, A. A.; HORVARTH, E. H.; MOORE, D. G.; REYBOLD, W. U. Use of slope, aspect, and elevation maps derived from digital elevation model data in making soil surveys. Madison: Soil Science Society of America. 1987. (SSSA Special Publication, 20).

15. McBRATNEY, A. B.; SANTOS, M. L. M.; MINASNY, B. On digital soil mapping. Geoderma, v. 117, p. 3-52, 2003.

16. McCUNE, B.; KEON, D. Equations for potential annual direct incident radiation and heat load. Journal of Vegetation Science, n. 13, p. 603-606. 2002.

17. MITASOVA, H.; HOFIERKA, J. Interpolation by Regularized spline with tension: II. application to terrain modeling and surface geometry analysis. Mathematical Geology, v. 25, p. 657-671, 1993.

18. MONTGOMERY, D. R. Predicting landscape-scale erosion using digital elevation models. Comptes Rendus Geoscience, v. 335, p. 1121-1130, 2003.

19. MOORE, I. D.; GEISSLER, P. E.; NIELSEN, G. A; PETERSON, G. A. Soil attribute prediction using terrain analysis. Soil Science Society of America Journal, v. 57, p. 443-452, 1993.

20. ODEH, I. O. A.; CHITTLEBOROUGH, D. J.; McBRATNEY, A. B. Elucidation of soil-landform interrelationships by canonical ordination analysis. Geoderma, v. 49, p. 1- 32, 1991.

21. PENNOCK, D. J.; ZEBARTH, B. J.; DE JONG, E. Landform classification and soil distribution in hummocky terrain, Saskatchewan, Canada. Geoderma, v. 40, p. 297-315, 1987.

22. SALAMUNI, E.; SALAMUNI, R.; EBERT, H. D. Contribuição à geologia da bacia sedimentar de Curitiba (PR). Boletim Paranaense de Geociências, Curitiba, n. 47, p. 123-142, 1999.

23. SUGAMOSTO, M. L. Uso de técnicas de geoprocessamento para elaboração do mapa de aptidão agrícola e avaliação da adequação de uso do Centro de Estações Experimentais do Canguiri, município de Pinhais - Paraná. 133 f Dissertação (Mestrado em Ciência do Solo) - Setor de Ciências Agrárias, Universidade Federal do Paraná, Curitiba, 2002.

24. VALERIANO, M. M. Curvatura vertical de vertentes em microbacias pela análise de modelos digitais de elevação. Revista Brasileira de Engenharia Agrícola e Ambiental, v. 7, n. 3, p. 539-546, 2003.

25. VALERIANO, M. M.; CARVALHO JÚNIOR, O, A. Geoprocessamento de modelos digitais de elevação para mapeamento da curvatura horizontal em microbacias. Revista Brasileira de Geomorfologia, v. 4, n. 1, p. 17-29, 2003.

Recebido em 28/09/2007 Aceito em 18/03/2008 

